\title{
AGRICULTURE AND NATURAL RESOURCES
}

Research article

\section{Effect of rhamnolipid-Aloe vera gel edible coating on post-harvest control of rot and quality parameters of 'Agege Sweet' orange}

\author{
Charles Oluwaseun Adetunji $\mathrm{i}^{\mathrm{a}, *, \dagger}$, Israel Sunmola Afolabi ${ }^{\mathrm{b}, \uparrow}$, Juliana Bunmi Adetunji $\mathrm{i}^{\mathrm{c}, \uparrow}$ \\ a Microbiology, Biotechnology and Nanotechnology Laboratory, Department of Microbiology, Edo University Iyamho, Edo State, Nigeria. \\ ${ }^{b}$ Covenant University, College of Science and Technology, Department of Biochemistry, Ogun State, Nigeria. \\ c Nutritional and Toxicological Research Laboratory, Department of Biochemistry Osun State University, Osogbo, Nigeria.
}

\section{Article Info}

\section{Article history:}

Received 18 December 2017

Revised 25 January 2019

Accepted 3 February 2019

Available online 30 August 2019

\section{Keywords:}

Aloe vera gel,

Citrus sinensis,

Edible coating,

Post-harvest management,

Rhamnolipid

\begin{abstract}
A local cultivar of sweet orange namely 'Agege sweet' constitutes a larger percentage among many citrus varieties planted in Nigeria, but there is a major setback in terms of extending its post-harvest shelf life. This work was designed to assess the effectiveness of a rhamnolipid coating to preserve the quality attributes of Agege sweet orange fruit during $8 \mathrm{wk}$ ambient storage compared with that of Aloe vera gel. Petri plates were supplied with different treatments (volume per volume, v/v) of Aloe vera gel $(0 \%, 0.5 \%, 1.0 \%, 1.5 \%, 2.0 \%, 2.5 \%)$ or rhamnolipid $(0 \%, 0.25 \%, 0.5 \%, 1.0 \%$, $1.5 \%, 2.0 \%$ ) and oranges were inoculated with a spore suspension of $P$. digitatum NSP01 spores. The solutions of rhamnolipid (2\%) and Aloe vera gel (2\%) were evaluated for their biocontrol activity on $P$. digitatum NSP01. The fruits were stored for $8 \mathrm{wk}$ at $25^{\circ} \mathrm{C}$. The lesion area, firmness, and chemical composition were assessed. The oranges coated with Aloe vera gel and rhamnolipid significantly $(p<0.05)$ prevented loss in firmness, total soluble solids and titratable acidity and reduced the decay caused by $P$. digitatum NSP01. Therefore, the newly formulated rhamnolipidAloe vera edible coating could serve as a permanent substitute for chemical fungicides used in the management of diseases and pests affecting agricultural productivity.
\end{abstract}

\section{Introduction}

A high rate of perishable losses in citrus fruits including oranges has been observed, because of the lack of adequate post-harvest management techniques which include significant losses due to poor storage conditions and about $25 \%$ of losses have been recorded in developed countries while $60 \%$ have been observed in developing countries (Mashav, 2010). The high rates of post-harvest decay and diseases have been linked to different fungal genera including Penicillium (Ilaria et al., 2017).
Several hazards and ecological imbalances have been reported to be associated with the synthetic chemicals, used in the management of decay and pests during the pre-harvest and post-harvest periods for fruits and vegetables, with some even causing harm during their application (Janisiewicz and Korsten, 2002). Moreover, due to increased concern and sensitization of the public toward food safety, there is a need to find a natural, safe and environmental-friendly means of controlling pest and diseases especially with biological origins (Shrivastava et al., 2017).

\footnotetext{
$\dagger$ Equal contribution.

* Corresponding author.

E-mail address: adetunjicharles@gmail.com. (C.O. Adetunji)
}

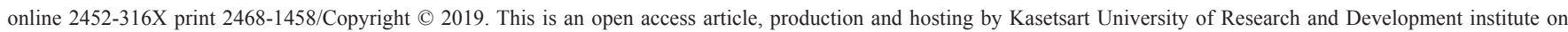
behalf of Kasetsart University. 
Edible coatings are one of the techniques used in post-harvest management for the preservation of fruits. They reduce microbial proliferation, delay dehydration, and prevent a high rate of transpiration from fruits and vegetables (Adetunji et al., 2014b; Waewthongrak et al., 2015). Aloe vera gel has been shown to contain an active ingredient with proven medicinal and therapeutic properties (Eshun and He, 2005). These unique properties make Aloe vera a candidate for edible coatings to prevent spoilage, reduce microorganism proliferation and maintain the quality of fruit during storage (MartínezRomero et al., 2006). The Aloe gel coating has been also shown to enhance the post-harvest quality of fruits (Adetunji et al., 2012a; Adetunji et al., 2012b; Adetunji et al., 2013; Benítez et al., 2013; Guillen et al., 2013; Adetunji et al., 2014a).

Rhamnolipids are microbially produced surfactants that have found applications in various sectors including with foods and medicines and especially in the area of agriculture for the management and elimination of plant pathogens. The major reasons behind their wide acceptability include low toxicity, surface-active properties and antimicrobial activities against several microbes as well as their “eco-friendly" properties (Silva et al., 2015).

Therefore, the present work was designed to evaluate the protective effects of Aloe vera gel alone and in combination with rhamnolipids on orange deterioration induced by Penicillium digitatum, as well as the effect of Aloe vera gel treatments on fungus-inoculated fruits, their quality and physiological attributes.

\section{Materials and Methods}

Raw material

Orange fruits (fully mature, green color, covered with thick wax) were harvested from a commercial orchard situated along the Ogbomosho ( $8^{\circ} 8^{\prime} 0^{\prime}$ 'N, $\left.4^{\circ} 16^{\prime} 0^{\prime \prime} \mathrm{E}\right)$ to Ilorin ( $\left.8^{\circ} 30^{\prime} 0^{\prime} \mathrm{N}, 4^{\circ} 33^{\prime} 0^{\prime \prime} \mathrm{E}\right)$ axis, and conveyed within $30 \mathrm{~min}$ to the postharvest laboratory at the Nigerian Stored Product Research Institute. Greenness, shape, uniformity in size, absence of injuries and color were carefully taken into consideration before picking oranges for the experiment, while spoiled and fruits that has been affected by diseases were removed. The orange fruits were later washed under running tap water, dipped in a chlorine solution $(0.0003 \%)$ for $30 \mathrm{~s}$ and then cleaned with distilled water.

\section{Source of microorganism}

Penicillium digitatum NSP01 was obtained from the culture collection (Microbiological Department of the Nigerian Stored Product Research Institute (NSPRI), Ilorin, Kwara State, Nigeria) as the test microorganism. A Penicillium digitatum NSP01 spore suspension was prepared by growing the fungus on potato-dextroseagar (PDA) plates maintained at $25^{\circ} \mathrm{C}$ for at least $14 \mathrm{~d}$, and thereafter harvesting spores by suspension in $9 \mathrm{~mL}$ of $0.85 \% \mathrm{NaCl}$ solution enhanced with Tween 80 at a concentration of $100 \mu \mathrm{L} / \mathrm{L}$. The spore concentration was determined using a hemocytometer and adjusted by dilution using sterile saline solution until a count of $1 \times 10^{5}$ from
Penicillium digitatum NSP01 spores was obtained. They were then stored at $4^{\circ} \mathrm{C}$ in tubes until needed. The strain $\mathrm{C} 1501$ was isolated from the rhizosphere of a wheat plant planted at the research farm of the NSPRI, Ilorin. The isolated strain was identified as Pseudomonas aeruginosa using 16s rRNA gene sequencing and coded C1501 with an accession number KF976394. The 16S rDNA gene sequence was submitted to GenBank (http;//www.ncbi.nlm.nih.gov). Strain C501 was incubated at $37^{\circ} \mathrm{C}$ for $48 \mathrm{hr}$ on King's agar in a Bio-Oxygen Demand incubator and it was later stored in the refrigerator at $4^{\circ} \mathrm{C}$ (Adetunji et al., 2017a).

\section{Preparation of Aloe vera gel}

The following procedure described by Adetunji et al. (2014a) was followed for the preparation of Aloe vera gel. A fully developed green leaf of Aloe vera plant was harvested and disinfected with sodium hypochlorite solution containing ( $25 \%$ volume for volume; v/v). The Aloe vera gel matrix was subsequently detached from the outer cortex of the leaves. The colorless gel-like material present was removed by filleting the Aloe vera plant. It was pulverized in a blender, and the subsequent combination was sieved to eliminate the fibers. The liquid acquired from fresh Aloe vera gel was used for this study. The gel medium was sterilized at $70^{\circ} \mathrm{C}$ for $45 \mathrm{~min}$, and this was allowed to cool to room temperature to allow the gel to stabilize. Ascorbic acid solution $(2.0 \mathrm{~g} / \mathrm{L})$ was then added before adding citric acid solution $(4.6 \mathrm{~g} / \mathrm{L})$ to keep the $\mathrm{pH}$ at 4 and it was later stored in a brown amber bottle to prevent oxidation.

\section{Preparation of culture and fermentation medium for the production} of rhamnolipid

The rhamnolipid-producing strain Pseudomonas aeruginosa (C1501) was cultured on a Cetrimide agar plate at $37^{\circ} \mathrm{C}$ for $14-16 \mathrm{hr}$ and then $50 \mathrm{~mL}$ of the liquid medium was utilized for the preparation of the inoculum development of strain $\mathrm{C} 1501$. This was then cultured at $37^{\circ} \mathrm{C}$ and 200 revolutions per minute (rpm) for $14-16 \mathrm{hr}$. The process described by Onkar et al. (2015) was afterward followed to prepare the liquid fermentation medium. The liquid fermentation was carried out using $40 \mathrm{~g} / \mathrm{L}$ glucose as a carbon source for the basal medium according to the methodology stated by Rufino et al. (2014). The fermentation was performed at $37^{\circ} \mathrm{C}$ and $200 \mathrm{rpm}$, respectively with a $\mathrm{pH}$ of 6.8 (Moussa et al., 2014).

\section{Extraction of rhamnolipid}

The $\mathrm{pH}$ of the residual supernatant from the fermentation medium was calibrated to 2.0 with $1 \mathrm{~N}$ hydrochloric acid for the precipitation of rhamnolipids. The resultant precipitation was obtained using centrifugation $(9000 \times g$ for 20 mins.) and was then extracted three times with ethyl acetate $(2: 1 \% \mathrm{v} / \mathrm{v})$. The organic phase was removed and the remaining leftover water in the solution was removed in a rotary evaporator which later formed rhamnolipids (Saravanan and Vijayakumar, 2014). The crude rhamnolipids product was then refined 
by means of the subsequent chromatographic processes established by Darvishi et al. (2011). The solvent used in eluting the crude rhamnolipid was n-hexane in a column $90(1.5 \mathrm{~cm} \times 35 \mathrm{~cm})$ containing silica gel 60 . The following solvents were utilized for the elution of the rhamnolipid as the polarity increased: chloroform, hexane, chloroform, methanol and acetone. Thin layer chromatography was utilized for the removal of the different constituents after concentrating them in a rotary evaporator in a solvent system containing chloroform:methanol:20\% aqueous acetic acid in the ratio 65:15:2 (Franzetti et al., 2014). The resulting rhamnolipid was established using reagents specific for sugars or fatty acids on thin layer chromatography.

\section{Purification and characterization of rhamnolipid}

The acquired crude extract was subsequently mixed with $50 \%$ ethanol, after which it was filtered through the process of ultrafiltration membrane of $30 \mathrm{kDa}$ molecular weight cut-off. The filtrate acquired after ultrafiltration was precipitated with acid after which it was dissolved in sterilized deionized water and was later filtered through a $1 \mathrm{kDa}$ membrane. This process was executed again to ensure purified rhamnolipid after it has been lyophilized. This was later thawed in deutrimethanol and the purified rhamnolipid was later characterized using nuclear magnetic resonance spectroscopy techniques based on the procedure developed by Adetunji et al. (2017b).

\section{In vitro Experiments}

The Aloe vera gel $(0.5 \% \mathrm{v} / \mathrm{v}, 1.0 \% \mathrm{v} / \mathrm{v}, 1.5 \% \mathrm{v} / \mathrm{v}, 2.0 \% \mathrm{v} / \mathrm{v}, 2.5 \%$ $\mathrm{v} / \mathrm{v})$ and the rhamnolipid $(0.25 \% \mathrm{v} / \mathrm{v}, 0.5 \% \mathrm{v} / \mathrm{v}, 1.0 \% \mathrm{v} / \mathrm{v}, 1.5 \% \mathrm{v} / \mathrm{v}$, $2.0 \% \mathrm{v} / \mathrm{v}, 2.5 \% \mathrm{v} / \mathrm{v}$.) solutions were mixed om PDA plates with the control plates not having any treatment. Radial mycelial inhibition was carried out by placing an agar disk containing $P$. digitatum NSP01 at the centre of each Petri dish. The diameter of the radial growth of $P$. digitatum NSP01 was later measured using a transparent meter rule. The Petri plates were incubated at $25^{\circ} \mathrm{C}$ for $7 \mathrm{~d}$. In addition, the percentage of conidial inhibition was determined using the same concentrations as described above but $20 \mu \mathrm{L}\left(1 \times 10^{6}\right.$ spore $\left./ \mathrm{mL}\right)$ of the spore suspension from $P$. digitatum NSP01 were grown in potato-dextrose broth. The percentage germination was determined by placing the spore from the treated and untreated samples on clean microscope glass slides and the rate of germination was observed with the aid of light microscopy using a magnification of $40 \times$ after $72 \mathrm{hr}$ incubation. The total number of germinated spores after treatment with Aloe vera gel $(0.5 \% \mathrm{v} / \mathrm{v}, 1.0 \% \mathrm{v} / \mathrm{v}, 1.5 \% \mathrm{v} / \mathrm{v}, 2.0 \% \mathrm{v} / \mathrm{v}, 2.5 \% \mathrm{v} / \mathrm{v})$ and the rhamnolipid $(0.25 \% \mathrm{v} / \mathrm{v}, 0.5 \% \mathrm{v} / \mathrm{v}, 1.0 \% \mathrm{v} / \mathrm{v}, 1.5 \% \mathrm{v} / \mathrm{v}, 2.0 \%$ $\mathrm{v} / \mathrm{v}, 2.5 \% \mathrm{v} / \mathrm{v})$ was calculated using: $(\mathrm{C}-\mathrm{T}) / \mathrm{C} \times 100$, where $\mathrm{C}$ is the number of spores from $P$. digitatum NSP01 in the potato-dextrose medium without any amendment and $\mathrm{T}$ is the number of spores from $P$. digitatum NSP01 in the potato-dextrose medium with various treatments from the Aloe vera gel and rhamnolipid solutions.
In vivo Experiments and evaluation of disease development

This experiment was conducted in the laboratory using the sterilized oranges as described above. A sterilized cork borer was used to create a wound ( $2 \mathrm{~mm}$ deep and $5 \mathrm{~mm}$ wide in the equatorial region) on the orange surface. The wounded site was inoculated with $20 \mu \mathrm{L}$ of the treatments from the Aloe vera gel $(0.5 \% \mathrm{v} / \mathrm{v}, 1.0 \%$ $\mathrm{v} / \mathrm{v}, 1.5 \% \mathrm{v} / \mathrm{v}, 2.0 \% \mathrm{v} / \mathrm{v}, 2.5 \% \mathrm{v} / \mathrm{v})$ and the rhamnolipid $(0.25 \% \mathrm{v} / \mathrm{v}$, $0.5 \% \mathrm{v} / \mathrm{v}, 1.0 \% \mathrm{v} / \mathrm{v}, 1.5 \% \mathrm{v} / \mathrm{v}, 2.0 \% \mathrm{v} / \mathrm{v}, 2.5 \% \mathrm{v} / \mathrm{v})$ solutions while the control treatment was inoculated with $20 \mu \mathrm{L}$ of sterilised distilled water and allowed to dry $4 \mathrm{hr}$. The wound area was later inoculated with $20 \mu \mathrm{L}$ of spore suspension containing $1 \times 10^{5} \mathrm{~mL}$ of spores of $P$. digitatum NSP01 while distilled water was used to inoculate the oranges serving as the control. The treated and the untreated oranges were later stored at room temperature $\left(25^{\circ} \mathrm{C}\right)$ for $8 \mathrm{hr}$ to allow the surface to dry. They were later stored in a plastic basket with a covered lid at $25^{\circ} \mathrm{C}$ for $7 \mathrm{~d}$. The inoculated wounds were later covered with parafilm to sustain moistness and incubated at $25^{\circ} \mathrm{C}$ for $7 \mathrm{~d}$ sealed in polyethylene-lined plastic boxes to retain high humidity. Detached fruits were evaluated for disease severity by measuring the length and width of each lesion area for $8 \mathrm{wk}$ after inoculation. The experiment was carried out in triplicate with 10 orange fruits in a complete randomized pattern (Adetunji and Fawole, 2012).

\section{Treatments of orange samples before storage at ambient temperature}

The following treatments were used during the in vivo experiment: Four different sets of orange fruits were given the following treatments each: oranges in the first (T1) and the second (T2) groups were dipped in $2 \%$ Aloe vera, and $2 \%$ rhamnolipid only, respectively. The third set of oranges (T3) was left uncoated but dipped in distilled water to serve as the control. The treatment was applied for $10 \mathrm{~min}$ after which the oranges were withdrawn and allowed to air dry for $1 \mathrm{hr}$ at room temperature. All the fruits in each set were stored at $25^{\circ} \mathrm{C}$ for $8 \mathrm{wk}$.

\section{Firmness}

The firmness of the orange was tested using a penetrometer, with a probe of $8 \mathrm{~mm}$ in diameter, which was forced slowly into the surface of each orange. The result obtained was expressed in kilograms per square centimeter.

\section{Ascorbic acid content}

The method described by Adetunji et al. (2014a,b) using 2, 6-dichlorophenolindophenol dye was utilized in the assessment of the total amount of L-ascorbic acid available in each orange pulp tissue sample and the results were expressed as milligrams of ascorbic acid equivalent per $100 \mathrm{~g}$ fresh weight. 


\section{Measurements of total soluble solid}

The total soluble content (TSS) in pulp was evaluated using a hand refractometer and stated as ${ }^{\circ}$ Brix.

\section{Measurements of titratable acidity in the pulp}

The titratable acid in the pulp juice was evaluated using the the techniques developed by Serrano et al. (2005). First, $5.0 \mathrm{~g}$ of orange pulp juice was mixed with $50 \mathrm{~mL}$ of sterilized water and then titrated with $0.1 \mathrm{M} \mathrm{NaOH}$ and stated as the percentage of citric acid.

\section{Statistical analysis}

All data were obtained in triplicate and analyzed using analysis of variance with the SPSS version 16.0 statistical package (SPSS Inc.; Chicago, IL, USA) (SPSS, 2007) and significant difference $(p<0.05)$ among means were separated using Duncan's multiple range test.

\section{Results}

The controls were represented by $0.00 \%$ concentration of the treatments. The results revealed that the higher the concentration, the better the effect of the rhamnolipid and Aloe vera gel. In addition, the rhamnolipid was more effective than the Aloe vera gel. The best results were obtained with rhamnolipid for days $0-2$ at $0.5 \%, 0-3$ days at $1.0 \%, 0-4$ days at $1.5 \%, 0-5$ days at $2.0 \%$ and $0-6$ days at $2.5 \%$ concentrations (Table 1).

The logarithmic value at which rhamnolipid exhibits inhibition against spores of $P$. digitatum NSP01 was represented by $\mathrm{y}=1,032$ $\ln (\mathrm{x})-2,475$, where $\mathrm{R}^{2}=0.7998$ while it was represented by $\mathrm{y}=$ $534.19 \ln (\mathrm{x})-1340.8$, where $\mathrm{R}^{2}=0.7612$ for the edible coating from Aloe vera gel. The variance between the types of activities demonstrated by the rhamnolipid and Aloe vera gel was investigated for more understanding. The diameters of the mycelia of $P$. digitatum NSP01 were plotted against the incubation time for each concentration of the edible coating tested during this study, attributing $0 \%$ for the concentration of the control sample. The $t$ test distribution indicated the intercepts of each linear regression defined the activities of each concentration from the edible coating tested during this study (Figs. 1A and B)

The effect of the different rhamnolipid and Aloe vera gel treatments at different concentrations on inhibition (\%) of conidial germination of $P$. digitatum NSP01 incubated at ambient temperature for $12 \mathrm{~h}$. is shown in Table 2. The higher the concentration, the greater was the effect on germination inhibition. No significant difference was observed in values obtained in rhamnolipid at 2.0 and 2.5 concentrations.

\section{Physicochemical analyses}

\section{Firmness}

The oranges treated with edible coating from Aloe vera gel and rhamnolipid had significantly higher firmness compared to the uncoated oranges during the $8 \mathrm{wk}$ of storage (Fig 2A). Moreover, it was discovered that the rhamnolipid coating had significantly higher ability to preserve firmness than did the Aloe vera gel.

\section{Ascorbic acid content}

Oranges treated with both coatings from rhamnolipid and Aloe vera contained significantly higher levels of ascorbic acid. The oranges treated with coating from Aloe vera gel had a higher ascorbic acid content than the rhamnolipid-coated fruits

\section{Titratable acidity}

The titratable acidity generally decreased as the storage time progressed in both the coated and the uncoated orange fruits (Fig. 2D). The titratable acidity in the rhamnolipid-coated fruit was higher than that of the Aloe vera gel at the end of the $8 \mathrm{wk}$ of storage. Titratable acidity in both coatings compared well with the control for the first 2 wk storage. The values of the titratable acidity in both coatings were significantly higher than the control after the $5^{\text {th }}$ week of storage.

\section{Total soluble solids}

The TSS in the untreated fruit was significantly higher than in the two coated fruits during storage. The rhamnolipid-coated oranges had significantly higher TSS values compared to the oranges coated with the Aloe vera gel (Fig. 2B). The two edible coatings containing $2 \%$ rhamnolipid and $2 \%$ Aloe vera gel were able to control the $P$. digitatum NSP01 spore suspension, which was evaluated in terms of the lesion area on the inoculated oranges (Table 3). The 2\% rhamnolipid and $2 \%$ Aloe vera gel coatings significantly lowered the growth of $P$. digitatum NSP01 throughout the experimental period. The correlation between fruit firmness and lesion size in oranges coated with $2 \%$ rhamnolipid and $2 \%$ Aloe vera gel when inoculated with $P$. digitatum NSP01 spore suspension produced regression coefficients of $\mathrm{R}^{2}=0.9186$ and $\mathrm{R}^{2}=0.863$ respectively. Moreover, the oranges inoculated with $P$. digitatum NSP01 spores without any coating application produced a regression coefficient of $\mathrm{R}^{2}=0.8246$ (Figs. 3A, B and C).

\section{Discussion}

The antimicrobial effect observed based on the rhamnolipid on strain C1501 may have been due to the presence of the mono-rhamnolipid (MRL) and di-rhamnolipid (DRL) congeners detected on thin layer chromatography. The MRL and DRL congeners showed that they synergetically influenced the antimicrobial activity on the tested pathogen ( $P$. digitatum NSP01) during this study (Das et al., 2014; Yan et al., 2014). Similar observations were reported by Arutchelvi et al. (2011), that the high levels of antimicrobial activity against the tested pathogens were due to the ratio of mono-rhamnolipid (MRL) and di-rhamnolipid (DRL) congeners contained in the rhamnolipids from Pseudomonas sp. IMP67 used in their study. 
Table 1 Average diameter (mean $\pm \mathrm{SD}$; in millimeters) of colonies developed during $7 \mathrm{~d}$ following the inoculation of $P$. digitatum NSP01 in Petri dishes treated with rhamnolipid and Aloe vera gel at different concentrations

\begin{tabular}{|c|c|c|c|c|c|c|c|}
\hline \multirow{2}{*}{ Treatment } & \multirow{2}{*}{$\begin{array}{l}\text { Number } \\
\text { of days }\end{array}$} & \multicolumn{6}{|c|}{ Concentration (\% volume per volume) } \\
\hline & & 0.00 & 0.50 & 1.00 & 1.50 & 2.00 & 2.50 \\
\hline \multirow{8}{*}{ RL } & 0 & $0.00 \pm 0.00^{\mathrm{h}}$ & $0.00 \pm 0.00^{\mathrm{e}}$ & $0.00 \pm 0.00^{\mathrm{b}}$ & $0.00 \pm 0.00^{\mathrm{b}}$ & $0.00 \pm 0.00^{\mathrm{b}}$ & $0.00 \pm 0.00^{\mathrm{b}}$ \\
\hline & 1 & $5.38 \pm 0.20^{\mathrm{g}}$ & $0.00 \pm 0.00^{\mathrm{e}}$ & $0.00 \pm 0.00^{\mathrm{b}}$ & $0.00 \pm 0.00^{\mathrm{b}}$ & $0.00 \pm 0.00^{\mathrm{b}}$ & $0.00 \pm 0.00^{\mathrm{b}}$ \\
\hline & 2 & $10.21 \pm 0.81^{\mathrm{f}}$ & $0.00 \pm 0.00^{\mathrm{e}}$ & $0.00 \pm 0.00^{\mathrm{b}}$ & $0.00 \pm 0.00^{\mathrm{b}}$ & $0.00 \pm 0.00^{\mathrm{b}}$ & $0.00 \pm 0.00^{\mathrm{b}}$ \\
\hline & 3 & $17.63 \pm 1.14^{\mathrm{e}}$ & $1.21 \pm 0.10^{\mathrm{d}}$ & $0.00 \pm 0.00^{\mathrm{b}}$ & $0.00 \pm 0.00^{\mathrm{b}}$ & $0.00 \pm 0.00^{\mathrm{b}}$ & $0.00 \pm 0.00^{\mathrm{b}}$ \\
\hline & 4 & $25.63 \pm 0.98^{d}$ & $1.93 \pm 0.40^{\mathrm{c}}$ & $1.14 \pm 0.62^{\mathrm{a}}$ & $0.00 \pm 0.00^{\mathrm{b}}$ & $0.00 \pm 0.00^{\mathrm{b}}$ & $0.00 \pm 0.00^{\mathrm{b}}$ \\
\hline & 5 & $38.45 \pm 1.02^{\mathrm{c}}$ & $2.64 \pm 1.01^{\mathrm{b}}$ & $1.18 \pm 0.35^{\mathrm{a}}$ & $1.10 \pm 0.71^{\mathrm{a}}$ & $0.00 \pm 0.00^{\mathrm{b}}$ & $0.00 \pm 0.00^{\mathrm{b}}$ \\
\hline & 6 & $46.78 \pm 1.01^{b}$ & $2.73 \pm 0.74^{b}$ & $1.20 \pm 0.73^{\mathrm{a}}$ & $1.12 \pm 0.30^{\mathrm{a}}$ & $1.09 \pm 0.20^{\mathrm{a}}$ & $0.00 \pm 0.00^{\mathrm{b}}$ \\
\hline & 7 & $55.63 \pm 0.85^{\mathrm{a}}$ & $3.41 \pm 0.82^{\mathrm{a}}$ & $1.28 \pm 0.09^{\mathrm{a}}$ & $1.17 \pm 0.50^{\mathrm{a}}$ & $1.15 \pm 0.43^{\mathrm{a}}$ & $0.00 \pm 0.00^{\mathrm{a}}$ \\
\hline \multirow{8}{*}{ ALG } & 0 & $0.00 \pm 0.00^{\mathrm{h}}$ & $0.00 \pm 0.00^{\mathrm{g}}$ & $0.00 \pm 0.00^{\mathrm{g}}$ & $0.00 \pm 0.00^{f}$ & $0.00 \pm 0.00^{\mathrm{e}}$ & $0.00 \pm 0.00^{\mathrm{d}}$ \\
\hline & 1 & $5.37 \pm 0.20^{\mathrm{g}}$ & $0.00 \pm 0.00^{\mathrm{g}}$ & $0.00 \pm 0.00^{\mathrm{g}}$ & $0.00 \pm 0.00^{\mathrm{f}}$ & $0.00 \pm 0.00^{\mathrm{e}}$ & $0.00 \pm 0.00^{\mathrm{d}}$ \\
\hline & 2 & $10.21 \pm 1.15^{\mathrm{f}}$ & $1.63 \pm 0.27^{\mathrm{f}}$ & $1.54 \pm 0.84^{\mathrm{f}}$ & $0.00 \pm 0.00^{\mathrm{f}}$ & $0.00 \pm 0.00^{\mathrm{e}}$ & $0.00 \pm 0.00^{\mathrm{d}}$ \\
\hline & 3 & $17.63 \pm 1.01^{\mathrm{e}}$ & $3.45 \pm 0.88^{\mathrm{e}}$ & $2.63 \pm 0.28^{\mathrm{e}}$ & $1.34 \pm 0.70^{\mathrm{e}}$ & $0.00 \pm 0.00^{\mathrm{e}}$ & $0.00 \pm 0.00^{\mathrm{d}}$ \\
\hline & 4 & $25.63 \pm 0.97^{\mathrm{d}}$ & $5.21 \pm 0.62^{\mathrm{d}}$ & $3.14 \pm 0.91^{\mathrm{d}}$ & $2.45 \pm 0.43^{\mathrm{d}}$ & $1.03 \pm 0.30^{\mathrm{d}}$ & $0.00 \pm 0.00^{\mathrm{d}}$ \\
\hline & 5 & $38.45 \pm 2.03^{\mathrm{c}}$ & $7.38 \pm 0.61^{\mathrm{c}}$ & $5.25 \pm 0.36^{\mathrm{c}}$ & $2.78 \pm 0.19^{\mathrm{c}}$ & $2.81 \pm 0.53^{c}$ & $1.00 \pm 0.01^{\mathrm{c}}$ \\
\hline & 6 & $46.78 \pm 1.12^{\mathrm{b}}$ & $10.21 \pm 1.03^{b}$ & $6.21 \pm 0.95^{\mathrm{b}}$ & $4.39 \pm 0.67^{b}$ & $3.14 \pm 0.11^{\mathrm{b}}$ & $1.21 \pm 0.06^{\mathrm{b}}$ \\
\hline & 7 & $55.63 \pm 0.68^{a}$ & $14.69 \pm 0.53^{\mathrm{a}}$ & $7.81 \pm 0.47^{\mathrm{a}}$ & $5.63 \pm 0.14^{\mathrm{a}}$ & $4.56 \pm 0.86^{\mathrm{a}}$ & $1.34 \pm 0.32^{\mathrm{a}}$ \\
\hline
\end{tabular}

$\mathrm{RL}=$ Rhamnolipid; $\mathrm{ALG}=$ Aloe vera gel.

Means with different superscripts within the same column are significantly different $(p<0.05)$.
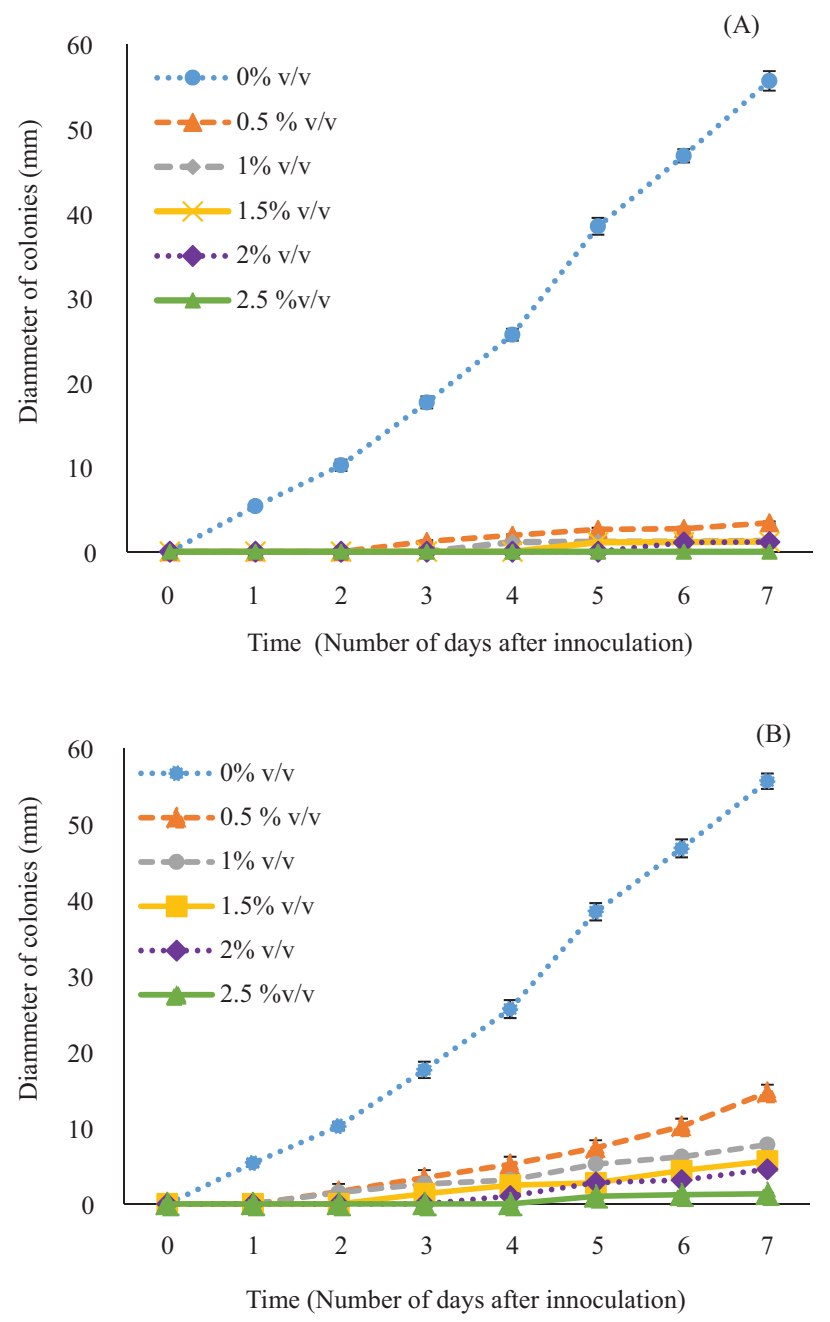

Fig. 1 Effect of rhamnolipid (A) and Aloe vera gel (B) treatments at various concentrations on in vitro mycelial growth of $P$. digitatum NSP01 during a 7-d incubation period under $25^{\circ} \mathrm{C}$ ambient conditions, where each value is the mean of three replicates $\pm \mathrm{SE}$.
Table 2 Effect of different rhamnolipid and Aloe vera gel treatments at different concentrations on inhibition (mean $\pm \mathrm{SD}$; percentage) of conidial germination of $P$. digitatum NSP01 incubated at ambient temperature for $72 \mathrm{hr}$

\begin{tabular}{lcc}
\hline \multirow{2}{*}{ Concentration } & \multicolumn{2}{c}{ Germination inhibition } \\
\cline { 2 - 3 } & \multicolumn{1}{c}{ RL } & \multicolumn{1}{c}{ ALG } \\
\hline 0.0 & $0.70 \pm 0.02^{\mathrm{e}}$ & $0.70 \pm 0.01^{\mathrm{f}}$ \\
0.5 & $1.93 \pm 0.10^{\mathrm{d}}$ & $1.21 \pm 0.16^{\mathrm{e}}$ \\
1.0 & $53.40 \pm 1.32^{\mathrm{c}}$ & $46.35 \pm 0.87^{\mathrm{d}}$ \\
1.5 & $98.50 \pm 2.41^{\mathrm{b}}$ & $61.25 \pm 1.34^{\mathrm{c}}$ \\
2.0 & $100.00 \pm 3.02^{\mathrm{a}}$ & $68.97 \pm 3.14^{\mathrm{b}}$ \\
2.5 & $100.00 \pm 3.82^{\mathrm{a}}$ & $78.36 \pm 2.01^{\mathrm{a}}$ \\
\hline
\end{tabular}

$\mathrm{RL}=$ Rhamnolipid $; \mathrm{ALG}=$ Aloe vera gel.

Means with different superscripts within the same column are significantly different $(p<0.05)$.

Table 3 Lesion areas (mean $\pm \mathrm{SD}$; square centimeters) on oranges treated with rhamnolipid and Aloe vera gel during storage

\begin{tabular}{lccc}
\hline \multirow{2}{*}{ Time (wk) } & \multicolumn{3}{c}{ Treatment } \\
\cline { 2 - 4 } & RL & ALG & Control \\
\hline 1 & $14.0 \pm 0.9^{\mathrm{b}}$ & $30.0 \pm 2.4^{\mathrm{a}}$ & $0.0 \pm 0.0^{\mathrm{c}}$ \\
2 & $28.0 \pm 3.2^{\mathrm{b}}$ & $35.0 \pm 2.6^{\mathrm{b}}$ & $44.0 \pm 5.2^{\mathrm{a}}$ \\
3 & $30.0 \pm 2.7^{\mathrm{c}}$ & $47.0 \pm 2.4^{\mathrm{b}}$ & $56.0 \pm 3.7^{\mathrm{a}}$ \\
4 & $33.0 \pm 1.8^{\mathrm{c}}$ & $63.0 \pm 3.2^{\mathrm{b}}$ & $47.0 \pm 4.2^{\mathrm{a}}$ \\
5 & $42.0 \pm 3.1^{\mathrm{c}}$ & $68.0 \pm 1.9^{\mathrm{b}}$ & $99.0 \pm 5.2^{\mathrm{a}}$ \\
6 & $48.0 \pm 2.5^{\mathrm{c}}$ & $70.0 \pm 2.6^{\mathrm{b}}$ & $102.0 \pm 5.9^{\mathrm{a}}$ \\
7 & $53.0 \pm 2.4^{\mathrm{c}}$ & $83.0 \pm 3.5^{\mathrm{b}}$ & $123.4 \pm 4.7^{\mathrm{a}}$ \\
8 & $55.0 \pm 3.8^{\mathrm{c}}$ & $85.0 \pm 2.7^{\mathrm{b}}$ & $143.6 \pm 7.2^{\mathrm{a}}$ \\
\hline
\end{tabular}

$\mathrm{RL}=$ Rhamnolipid; $\mathrm{ALG}=$ Aloe vera gel.

Means with different superscripts within the same column are significantly different $(p<0.05)$. 

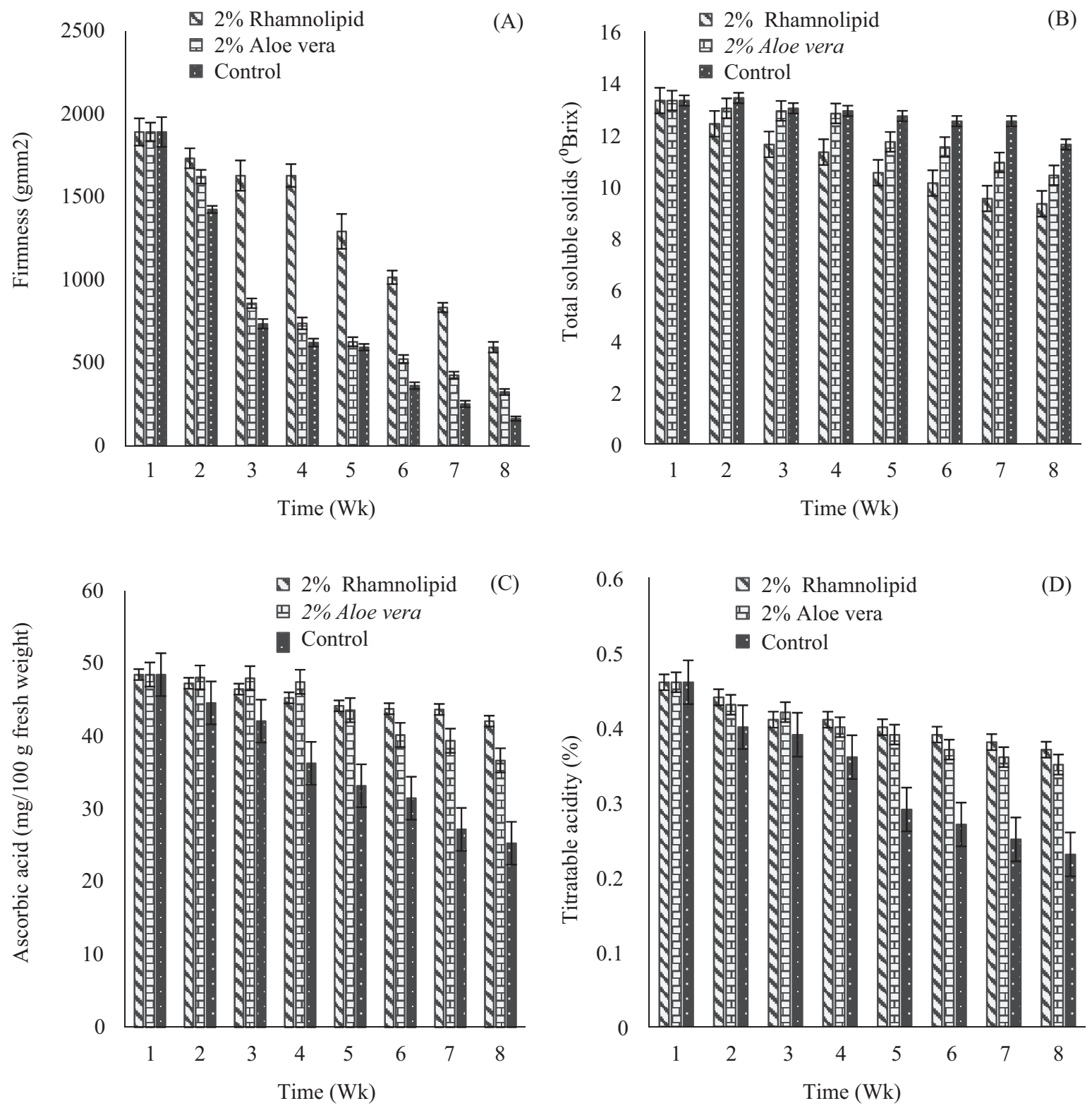

Fig. 2 Effect of Aloe vera gel and rhamnolipid coating on orange fruit during storage at $25^{\circ} \mathrm{C}$ : (A) firmness; (B) total soluble solids; (C) ascorbic acid content; (D) titratable acidity, where each value is the mean of three replicates $\pm \mathrm{SE}$ 

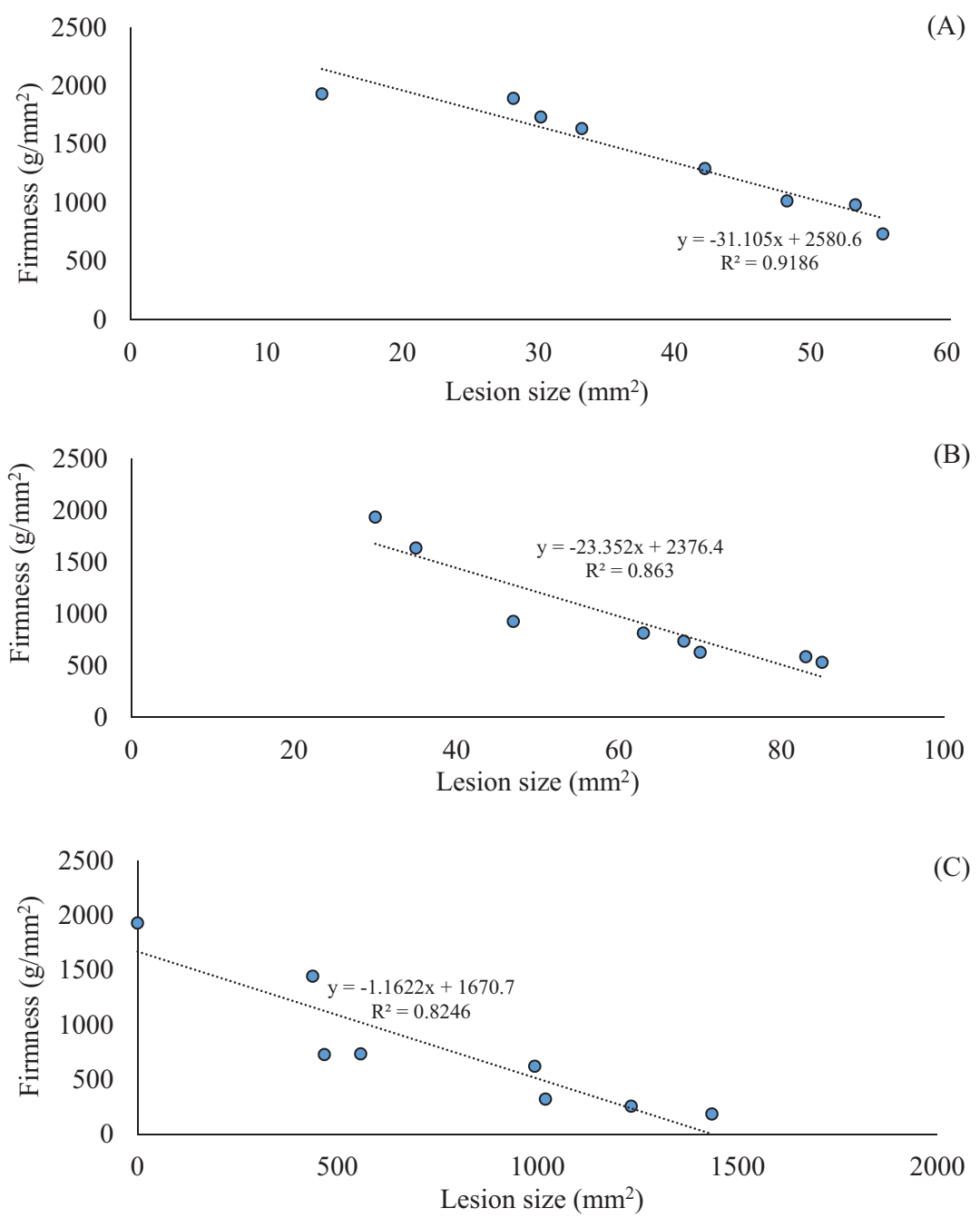

Fig. 3 Regression curves for relationship between lesion size and fruit firmness in inoculated and un-inoculated oranges: (A) oranges treated with $2 \%$ rhamnolipid; (B) oranges treated with $2 \%$ Aloe vera; (C) oranges inoculated with P. digitatum NSP01 spores without any treatment used as a control.

During the current study, it was established that the combinatory effect of rhamnolipid and Aloe vera gel was effective in controlling the spoilage induced by $P$. digitatum NSP01. The successful control of postharvest gray mold of table grapes with a preharvest and postharvest application of a formulation consisting of Aloe vera gel coating had been reported by Serrano et al. (2006) and Castillo et al. (2010). Both the edible coating based on Aloe vera gel and rhamnolipid used during the current study preserved all the quality parameters tested, also reducing microorganism proliferation (Martínez-Romero et al., 2006; Serrano et al., 2006; Valverde et al., 2005).

The Aloe vera gel and rhamnolipid coatings effectively prevented the loss of firmness in stored fruits (Fig. 2A). Aloe vera gel and rhamnolipid were effective in reducing pectin depolymerization and microbial proliferation in coated fruit (Guillen et al., 2013). In addition, the combination coating on the oranges produced a better firmness, which might have been due to the elastic behavior of the coating material that enhanced the total pectin content and the hardness values of the fruits during storage (Benítez et al., 2013). Aloe vera, as an edible coating, was previously very effective in reducing the transpiration process and softening in sweet cherry and table grapes during storage by lowering weight loss and preserving fruit firmness (Valverde et al., 2005; Martínez-Romero et al., 2006). The ability to retain firmness can be attributed to the ability of the coating to reduce gas diffusion through the fruit's skin, reduce the respiration rate and ethylene emission that normally leads to delays in the fruit's metabolism (Valero and Serrano, 2010).

The levels of titratable acidity and ascorbic acid in oranges diminished gradually after harvest (Figs. 2C and 2D), with the decrease in their levels during storage being related with a sharp increase in senescence. The reduction of titratable acidity in fruits is correlated with the reduction of organic acid levels during the ripening process by their oxidation through the Krebs cycle to form energy reserves for fruits (Kays, 1991). 
The lower TSS content observed in the rhamnolipid-treated oranges (Fig. 2B) was possibly due to the decrease in respiration processes and metabolic activity, therefore delaying the ripening process. These results were in agreement with earlier reports for mangoes and papayas coated with chitosan (Ali et al., 2011).

Fruit firmness has been established as an important causative factor for resistance against spoilage (Blazek et al., 2007). Thus, the preserved fruit firmness in treated oranges was correlated with extended postharvest time and fruit maturity in orange varieties (Olmo et al., 2000). This characteristic suggests that fruit maturity is correlated to mechanical properties and fruit quality (Ladaniya, 2008).

In conclusion, the edible coatings from Aloe vera gel and rhamnolipid were good agents for controlling $P$. digitatum (NSP01) and may serve as an alternative or total replacement for the chemical based wax coatings often used for the prevention of postharvest loss. The active compound involved in inducing resistance to spoilage needs to be further characterized and its mechanism needs further study.

\section{Conflict of Interest}

The authors declare that there are no conflicts of interest.

\section{Acknowledgements}

This study was partially funded by the Council of Scientific and Industrial Research (CSIR), New Delhi, India. The World Academy of Science (TWAS), Italy (FR number: 3240267282), supported part of this work, especially the characterization of the rhamnolipid. The authors appreciate the management of NSPRI for allowing use of their facilities at Ilorin, Kwara State, Nigeria. Special thanks are recorded to Mr. Alao Tayo and Mr. Issa Funsho Habeeb for their technical support.

\section{References}

Adetunji, C.O., Fawole, O.B. 2012. In vitro of crude extract of Jatropha curcas on Aspergillus niger $v$. tieghem association with post harvest rot of onion bulb. Int. J. Phytofuels Allied Sci. 1: 1-5.

Adetunji, C.O., Arowora, K.A., Fawole, O.B., Adetunji, J.B. 2013. Effects of coatings on storability of carrot under evaporative coolant system. Albanian J. Agric. Sci. 12: 485-493,

Adetunji, C.O., Fadiji, A.E., Aboyeji, O.O. 2014a. Effect of chitosan coating combined Aloe vera gel on cucumber (Cucumis sativa L.) post-harvest quality during ambient storage. J. Emerg. Trends Eng. Applied Sci. 5: 391-397.

Adetunji, C.O., Fawole, O.B., Oloke, J.K., Adetunji, J.B, Makanjuola, O.R. 2012a. Effect of edible coatings from Aloe vera gel on Citrus sinensis during ambient storage. J. Agric. Res. Dev. 11: 77-84.

Adetunji, C.O., Fawole, O.B., Arowora, K.A., Nwaubani, S.I. et al. 2012b. Effects of edible coatings from Aloe vera gel on quality and postharvest physiology of Ananas comosus (L.) fruit during ambient storage. Global J. Sci. Front. Res. Bio-Tech Genet. 12: 39-43.

Adetunji, C., Oloke, J., Kumar, A., Swaranjit, S., Akpor, B. 2017a. Synergetic effect of rhamnolipid from Pseudomonas aeruginosa $\mathrm{C} 1501$ and phytotoxic metabolite from Lasiodiplodia pseudotheobromae C1136 on Amaranthus hybridus L. and Echinochloa crus-galli weeds. Environ. Sci. Pollut. Res. Int. 24: 13700-13709. doi: 10.1007/s11356-017-8983-8.

Adetunji, C.O., Oloke, J.K., Pradeep, M., Jolly, R.S., Anil, K.S., Swaranjit, S.C., Bello, O. M. 2017b. Characterization and optimization of a rhamnolipid from Pseudomonas aeruginosa $\mathrm{C} 1501$ with novel biosurfactant activities. Sustainable Chem. Pharm. 6: 26-36.

Adetunji, C.O., Omojowo, F.S., Ajayi, E.S. 2014b. Effects of Opuntia cactus mucilage extract and storage under evaporative coolant system on the shelf life of Carica papaya fruits. J. Agrobiotechnol. 5: 49-66.

Ali, A., Muhammad, M.T.M., Sijam, K., Siddiqui, Y. 2011. Effect of chitosan coatings on the physicochemical characteristics of Eksotika II papaya (Carica papaya L.) fruit during cold storage. Food Chem. 124: 620-626.

Arutchelvi, J., Joseph, C., Doble, M. 2011. Process optimization for production of rhamnolipids and formation of biofilm by Pseudomonas aeruginosa CPCL on polypropylene. Biochem. Eng. J. 56: 37-45.

Benítez, S., Achaerandio, I., Pujola, M., Sepulcre, F. 2013. Aloe vera based edible coatings improve the quality of minimally processed 'Hayward' kiwifruit. Postharvest Biol. Technol. 8: 29-36.

Blazek, J., Opatova, H., Golias, J., Homutova, I. 2007. Ideotype of apples with resistance to storage diseases. Hort. Sci. (Prague). 34: 107-113.

Castillo, S., Navarro, D., Zapata, P.J., Guillén, F., Valero, D., Serrano, M., Martínez- Romero, D. 2010. Antifungal efficacy of Aloe vera gel in vitro and its use as a preharvest treatment to maintain postharvest table grape quality. Postharvest Biol. Technol. 57: 183-188.

Darvishi, P., Ayatollahi, S., Mowla, D., Niazi, A. 2011. Bio-surfactant production under extreme environmental conditions by an efficient microbial consortium, ERCPPI-2 Colloids Surf. B. Biointerfaces. 84: 292-300. doi: 10.1016/j.colsurfb.2011.01.011.

Das, P., Yang, X.P., Ma, L.Z. 2014. Analysis of biosurfactants from industrially viable Pseudomonas strain isolated from crude oil suggests how rhamnolipids congeners affect emulsification property and antimicrobial activity. Front. Microbiol. 5: 42-49. doi: 10.3389/fmicb.2014.00696.

Eshun, K., He, Q. 2005. Aloe vera: A valuable ingredient for the food, pharmaceutical and cosmetic industries: A review. Crit. Rev. Food Sci. Nutr. 44: 91-96.

Franzetti, A., Gandolfi, I., Fracchia, L., Van Hamme, J., Gkorezis, P., Marchant, R. 2014. Biosurfactant use in heavy metal removal from industrial effluents and contaminated sites. In: Kosaric, N., Sukan, F.V. (Eds.). Biosurfactants: Production and Utilization-Processes, Technologies, and Economics. CRC Press. Boca Raton, USA. pp. 361-366. doi: 10.1201/b17599-20

Guillen, F., Díaz-Mula, H.M., Zapata, P.J., Valero, D., Serrano, M., Castillo, S 2013. Aloe arborescens and Aloe vera gels as coatings in delaying postharvest ripening in peach and plum fruit. Postharvest Biol. Technol. 83: $54-57$.

Ilaria, P., Oscar, G., Maddalena, B., Tito, C., Vittorio, R., Laura, M. 2017. Combining biocontrol agents with different mechanisms of action in a strategy to control Botrytis cinerea on grapevine. J. Crop Prot. 97: 85-93.

Janisiewicz, W.J., Korsten, L. 2002. Biological control of postharvest diseases of fruits. Ann. Rev. Phytopathol. 40: 411-441.

Kays, S.J. 1991. Postharvest Physiology of Perishable Plant Products. Avi. Books. NewYork, NY, USA.

Ladaniya, M.S., 2008. Citrus fruit: Biology, Technology and Evaluation. Academic Press. San Diego, USA

Martínez-Romero, D., Alburquerque, N., Valverde, J.M., Guillén, F., Castillo, S., Valero, D., Serrano, M. 2006. Postharvest sweet cherry quality and safety maintenance by Aloe vera gel treatment: A new edible coating. Postharvest Biol. Technol. 39: 93-100. 
Mashav. 2010. Postharvest losses of fruits and vegetables. http//www.mashav. $\mathrm{mfa} . g o v .11 / \mathrm{mfm} / \mathrm{web} / \mathrm{main} /$ document.asp?document $\mathrm{ID}=42327,25$ January 2019.

Moussa, T.A.A., Mohamed, M.S., Samak, N. 2014. Production and characterization of di-rhamnolipid produced by Pseudomonas aeruginosa TMN. Braz. J. Chem. Eng. 31: 867-880.

Olmo, M., Nadas, A., Garcia, G.M. 2000. Non-destructive methods to evaluate maturity level oranges. J. Food Sci. 65: 365-369.

Onkar, N.T., Kangjam, S., Thiyam, B., et al. 2015. Isolation, identification and characterization of protease producing Bacillus spp. from unexplored ecosystems of Indo-Burma biodiversity hotspots. Int. J. Curr. Microbiol. App. Sci. 4: 611-622.

Rufino, R.D., Luna, J.M., de Campos Takaki, G.M., Sarubbo, L.A. 2014. Characterization and properties of the biosurfactant produced by Candida lipolytica UCP 0988. Electron. J. Biotechnol. 17: 34-38. doi: 10.1016/j. ejbt.2013.12.006.

Saravanan, V., Vijayakumar, S. 2014. Production of biosurfactant by Pseudomonas aeruginosa PB3A using agro-industrial wastes as a carbon source. Mal. J. Microbiol. 10: 57-62.

Serrano, M., Martínez-Romero, D., Castillo, S., Guillén, F., Valero, D. 2005. The use of natural antifungal compounds improves the beneficial effect of MAP in sweet cherry storage. Innov. Food Sci. Emerg. Technol. 6: $115-123$.
Serrano, M., Valverde, J.M., Guillen, F., Castillo, S., Martínez-Romero, D., Valero, D. 2006. Use of Aloe vera gel coating preserves the functional properties of table grapes. J. Agric. Food Chem. 54: 3882-3886.

Shrivastava, P., Kumar, R., Yandigeri, M.S. 2017. In vitro biocontrol activity of halotolerant Streptomyces aureofaciens K20: A potent antagonist against Macrophomina phaseolina (Tassi) Goid. Saudi J. Biol. Sci. 24: 192-199.

Silva, V.L., Lovaglio, R.B., Zuben, C.J.V., Contiero, J. 2015. Rhamnolipids: Solution against Aedes aegypti? Front. Microbiol. 6: 88. doi: 10.3389/ fmicb.2015. 00088.

SPSS. 2007. SPSS for Windows, Version 16.0. SPSS Inc. Chicago, IL, USA.

Valero, D., Serrano, M. 2010. Postharvest Biology and Technology for Preserving Fruit Quality. CRC Press, Boca Raton, USA.

Valverde, J.M., Valero. D., Martínez-Romero D., Guillén F., Castillo, S., Serrano. M. 2005. Novel edible coating based on Aloe vera gel to maintain table grape quality and safety. J. Agric. Food Chem. 53: 7807-7813.

Waewthongrak, W., Pisuchpen, S., Leelasuphakul, W. 2015 Effect of Bacillus subtilis and chitosan applications on green mold (Penicilium digitatum Sacc.) decay in citrus fruit. Postharvest Biol. Technol. 99: 44-49.

Yan, F., Xu, S., Chen, Y., Zheng, X. 2014. Effect of rhamnolipids on Rhodotorula glutinis biocontrol of Alternaria alternata infection in cherry tomato fruit. Postharvest Biol. Technol. 97: 32-35. 